\title{
Design Optimization and Analysis of Industrial Gearbox Casing to Reduce Wear of Gear and Bearings Due to Vibrations: Review
}

\author{
Toshita Dhande ${ }^{1}$, R. B. Patil ${ }^{2}$ \\ ${ }^{1}$ M.E. Student, MGM's Jawaharlal Nehru Engineering College, Aurangabad, India \\ ${ }^{2}$ Associate Professor, MGM's Jawaharlal Nehru Engineering College, Aurangabad, India
}

\begin{abstract}
Gearbox casing is the important part of the pipe pulling machine. Vibrations are created in gear box casing while the machine is in operation causing the failure of bearing and worm gear in the gearbox. To improve the life of the bearing and worm gear it is necessary to reduce the vibrations. The vibrations are reduced by avoiding the resonance and optimization of gearbox casing. Gearbox casing is optimized by adjusting the shape and structure of housing, shape and thickness of stiffener. The aim of this study is to determine, verify and validate the vibration characteristics of the gearbox top cover using both analytical and experimental techniques. ANSYS software used to determine natural frequency response for gearbox casing. This analysis finds the natural frequency of casing. The results obtained are validated by FFT analyzer.
\end{abstract}

Keywords: Gearbox Casing, FFT analyzer, Modal analysis, Vibrations.

\section{Introduction}

The Gearboxes are used in machine system for speed variation. The gearbox casing covers the different sets of gears with their bearing so that the vibration created in gearbox do not damage the gears and bearing. The selected gearbox having 1:20 reduction ratio. Most of the noise and vibration are related to resonance. When the dynamic forces in the process excite the natural frequencies or modes of vibration in the surrounding structure then resonance occur in the system. Analysis of gearbox casing of pipe pulling machine is very essential in order to decide appropriate dimensions and to predict behavior of casing under different operating condition. ANSYS software used to determine natural frequency response of gearbox casing. The natural frequency is the frequency at which a system oscillates when it is distributed. This analysis is to find out the natural frequency of gearbox casing.

The casing encloses the worm and worm gear, three bearing to support the shafts. The bottom part of casing is filled with the oil. In the power transmission system, the vibrations generated at gear mesh are transmitted to gearbox housing through the shaft and bearings. The selected gearbox is used to pull rigid P. V. C. pipe at constant speed. The gearbox is connected to DC motor which having 1440 or 960 RPM about 1HP. The model of gearbox casing is created in SOLID EDGE and analyzes in ANSYS. This results are validate by the FFT analyzer.

\section{Literature Review}

Nigade et al. [1] done vibration analysis of gearbox top cover of integrally geared centrifugal compressor. They used modal analysis for extraction of mode shapes and natural frequency. Impact testing used for experimental validation. The result they found indicate the natural frequency of gearbox top cover predicted by FEA are within 8 percent of measured natural frequencies of the modal test data, thus confirming the close agreement between FEA and experimental data.

Patil and Pise [2] analyzed the differential gearbox casing of pick up van vehicle. They used modal and stress analysis and optimize the gearbox casing. The theoretical model analysis validated with experimental results from Fourier frequency transformer analysis. They obtained natural frequency of casing with constraints using ANSYS and compared with gear mesh frequency. The result they found is no resonance condition.

Vijaykumar et al. [3] performed the vibration analysis of gearbox casing using finite element analysis. They determine the natural vibration modes and forced harmonic frequency response for gearbox casing. They used two vibrational analysis techniques i.e. time domain analysis and frequency domain analysis. They successfully removes the noise from the gearbox vibration signal.

Syed Rizwan Ul haque et al. [4] done the static analysis of gearbox casing using submodelling approach in ANSYS. They carried out analysis in two different models global or coarse model and sub model. They proved sub modeling method gives optimum design, makes computations easy and high efficient.

D. S. Chavan et al. [5] discussed about the vibrations in harvester power take off gearbox. They have done modal analysis to measure natural frequencies and mode shapes of the structure. They done modal analysis for bevel gear shaft and found that it creates resonance with gear mesh frequency. They removed material from splined end of shaft and again do analysis and found improvement in result. They got range of frequency is out of gear mesh frequency range and avoid the resonance. 


\section{International Journal of Science and Research (IJSR) \\ ISSN (Online): 2319-7064}

Index Copernicus Value (2013): 6.14 | Impact Factor (2015): 6.391

Yaun H. Guan et al. [6] modelled the four actuation concepts for the active suppression of gearbox housing mesh frequency vibrations due to transmission error excitation from the gear pair system and compared by computing the required actuation forces and amplifier power spectra. They applied four different actuation concepts designed. They examined several key comparison criteria including the required actuation effort, control robustness and implementation cost and discussed the advantages and disadvantages of each concept. Based on the simulated data, they found the active shaft transverse vibration control scheme as the most suitable approach for this application.

Kostic and Ognjanovic [7] discussed about the noise emission of gear units (gearbox) depends both on the disturbances and on the insulating capabilities and modal behavior of housing. They found that the results of modal testing give the possibility of identification of noise structure for the chosen gearbox. Comparison and analysis of the results obtained lead to precise determination of the cause of creation of the total spectrum of gear transmission units.

Ashwani Kumar et al. [8] considered the vibration problem of truck transmission housing using FEA method. They studied the vibration pattern for first twenty modes. The analysis results shows the transmission housing is subjected to axial bending variation, torsional vibration, and axial bending with torsional vibration. They constrained the transmission housing motion by constraining the displacement of bolts holes.

Patel and Shah [9] done study of equivalent von- mises stress in linear \& outer gearbox casing with the coupled method has been done using ANSYS. They carried out this study to evaluate steady state thermal stress analysis. They proves that in practice thermal stress analysis is also important factor for optimum design and reverse engineering of any mechanical structure and system.

Vasim Bashir Maner et al. [10] discussed about the design and optimization for foot casing of gearbox. Foot casing is the part of gearbox. They reduce the excessive weight of foot casing. This study has been carried out to evaluate static analysis of gearbox foot casing using commercial software ANSYS. The results found are better than existing model.

Kostic and Markovic [11] performed modal displacement excitation in gear housing walls by finite element method in a large number of modal shapes (frequency) of natural oscillation. They used direct integration method within FEM. In experimental approach, impulse excitation was realized by impact method and response was measured at appropriate point by mean of an accelerometer \& FFT frequency analysis.

Choy et al. [12] have predicted the casing vibration by analytically and they compared this predicted casing vibrations to measured results from test rig. They found the natural frequency of simulated results were within 5 percentage of experimental values.
Khobragade and Priyadarshani [13] compared the analysis result of two simulation software i.e. Altair Hypermesh / Optistruct and ANSYS 11.0. The comparison obtained from results were closely matching. They used results obtained from analysis in developing an optimum design of gearbox casing. It has not only helped in building cost effective design but also have helped to reduce prototype development and testing time.

\section{Techniques Used}

\subsection{Modal Analysis using ANSYS}

Modal analysis is used to determine the vibration characteristics such as natural frequency and mode shapes of structure or machine component while it is being designed. It can also serve as a starting point for another, more detailed, dynamic analysis, such as a transient dynamic analysis, a harmonic analysis, or a spectrum analysis. The natural frequencies and mode shapes are important parameters in the design of a structure for dynamic loading conditions. They are also required if you want to perform a spectrum analysis or a mode-superposition harmonic or transient analysis. Modal analysis done on the pre-stressed structure. Another useful feature is modal cyclic symmetry, which allows you to review the mode shapes of a cyclically symmetric structure by modeling just a sector of it. Modal analysis in the ANSYS, Inc. family of products is a linear analysis. Any nonlinearities, such as plasticity and contact (gap) elements, are ignored even if they are defined [14].

\subsection{FFT Analyzer}

FFT analyzer is the essential tool in such fields as vibration and shock data analysis, machinery monitoring and analysis of complex waveforms. Use of the FFT analyzer is required in many industries, including military, transportation, aerospace, manufacturing and consumer products. Fourier analysis converts time (or space) to frequency and vice versa; an FFT rapidly computes such transformations by factorizing the DFT matrix into a product of sparse (mostly zero) factors. The FFT analyzer along with associated transducer such as accelerometers is the primary analysis tool used in vibrational experiment. FFT analyzer is the PC based system and operate in a familiar environment such as Windows 95. FFT analyzer uses constant bandwidth resolution. FFT analysis is a useful tool in sound and vibration analysis and is available in PULSE Lab Shop and the PULSE Reflex platform. FFT analysis uses the Fast Fourier Transformation algorithm to calculate a spectrum from a time domain signal, and is the most common type of spectral analysis tool available today [15].

\section{Conclusions}

Gearbox is a very important component in any machine. So as to increase the life of the gears and bearings in the gearbox assembly, vibration reduction in gearbox casing is of prime importance. An extensive research in the past clearly indicates that there is a huge scope for improvement in this field. The finite element simulation for modal analysis is the 


\section{International Journal of Science and Research (IJSR) \\ ISSN (Online): 2319-7064 \\ Index Copernicus Value (2013): 6.14 | Impact Factor (2015): 6.391}

most popular and commonly found method to find out the node shapes during vibrations. ANSYS is used in almost all cases for simulation. Some researchers used two simulation software and compared their results. Some used test rigs for experiment. Most researchers also used FFT analyzer to validate the results obtained by the simulation. It was seen that the simulation and experimental results are in close agreement with each other.

\section{References}

[1] R. V. Nigade, T.A.Jadhav, A.M.Bhide, Vibration Analysis of Gearbox Top Cover, International Journal of Innovations in Engineering and Technology (IJIET), Vol. 1, Issue 4, ISSN: 2319 - 1058, 2012, pp. 26-33, 2012.

[2] Shrenik M. Patil, Prof. S. M. Pise, Modal and Stress Analysis of Differential Gearbox Casing with Optimization, Journal of Engineering Research and Applications, ISSN: 2248-9622, Vol. 3, Issue 6, pp. 188193, 2013.

[3] Mr.Vijaykumar, Mr.Shivaraju, Mr.Srikanth, Vibration Analysis for Gearbox Casing using Finite Element Analysis, The International Journal Of Engineering And Science (IJES), Volume 3,Issue 2, ISSN (e): 2319 1813 ISSN (p): 2319 - 1805, pp. 18-36, 2014.

[4] Syed Rizwan Ul Haque, Prof. Dongyan Shi, Tauseef Ahmed, Static Analysis of Gearbox Casing using Submodeling Approach in ANSYS, Harbin Engineering University publication, China, pp. 15-22, 2010.

[5] D.S.Chavan, A.K.Mahale, Dr. A.G.Thakur, Modal Analysis of Power Take Off Gearbox, International Journal of Emerging Technology and Advanced Engineering, Volume 3, Issue 1, pp. 70-76, 2013.

[6] Yuan H. Guan, Mingfeng Li, Teik C. Lim, W. Steve Shepard Jr, Comparative Analysis of Actuator Concepts for Active Gear Pair Vibration Control, Journal of Sound and Vibration, 269, pp. 273-294, 2004.

[7] Snezana Ciric Kostic, Milosav Ognjanovic, The Noise Structure of Gear Transmission Units and the Role of Gearbox Walls, FME Transactions, Vol. 35, No 2, pp. 105-112, 2007.

[8] Ashwani Kumar, Himanshu Jaiswal, Avichal Pandey, Pravin P. Patil, Free Vibration Analysis of Truck Transmission Housing Based on FEA, 3rd international conference on materials processing and characterization, pp. 1588-1592, 2014.

[9] P. D. Patel, D. S. Shah, Steady State Thermal Stress Analysis of Gearbox Casing by Finite Element Method, International Journal of Mechanical and Industrial Engineering, Volume-2, Issue- 4, pp. 26-30, 2012.

[10]Vasim Bashir Maner, M. M. Mirza, Shrikant Pawar, Design Analysis and Optimization for Foot Casing of Gearbox, 3rd IRF International Conference, pp. 35-38, 2014.

[11]Snezana Ciric-Kostic, Svetislav Lj. Markovic, Modal Displacemet Excitation in Gear Housing Walls. pp. 2633.

[12] F. K. Choy, Y. F. Raun, Fred K. Choy, Yeefeng F. Raun, Modal Simulation of Gearbox Vibration with
Experimental Validation, NASA paper AIAA 92-3934, pp. 1- 15, 1992.

[13]T. N. Khobragade, Priadarshani P., Static Analysis of Gearbox Casing, Driving Innovation with Enterprise Solution, pp. 12-21, 2008.

[14]ANSYS Mechanical APDL Structural Analysis Guide, ANSYS inc., Southpointe, 275, Technology Drive, Canonsburg, PA 15317.

[15]The FFT Analyzer in Mechanical Engineering Education, Robert Frey, State University of New York, Binghamton, New York.

\section{Author Profile}

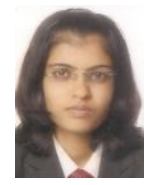

Toshita Dhande received B.E. degree in Mechanical Engineering from Government College of Engineering, Jalgaon in 2013. She is pursuing her M.E. in CAD/CAM from MGM's Jawaharlal Nehru Engineering College, Aurangabad.

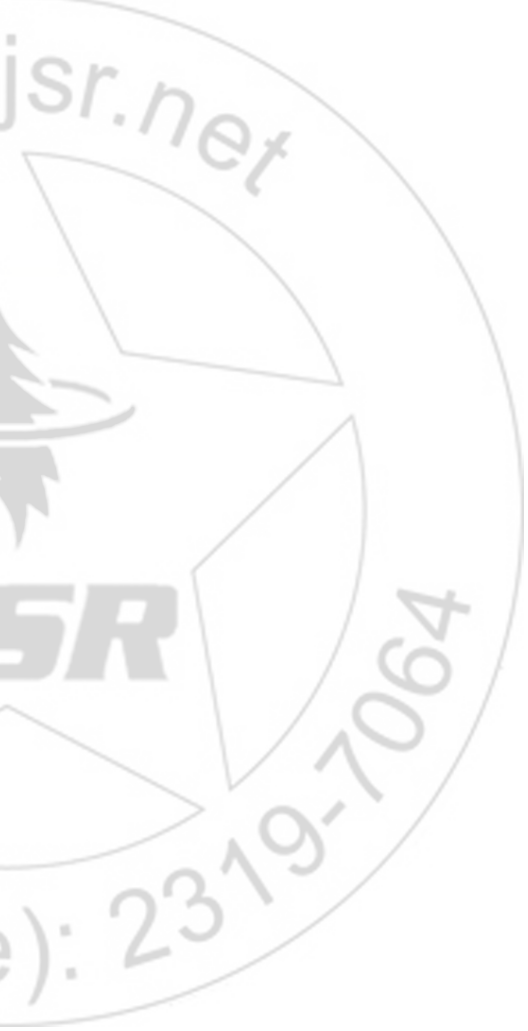

